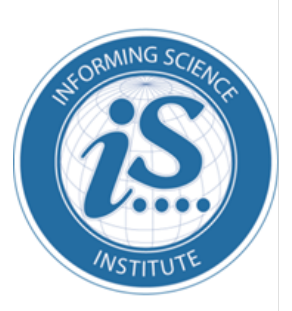

Proceedings of the Informing Science + Information Technology Education Conference

An Official Publication

of the Informing Science Institute

InformingScience.org

InformingScience.org/Publications

June 30 - July 4, 2019, Jerusalem, Israel

\title{
Professional LIFE OF INFORMATION SYSTEM GRADUATES-IMPRESSIONS AND EXPERIENCES
}

Georg Disterer

University of Applied Sciences and

georg.disterer@hs-hannover.de

Arts, Hannover, Germany

\section{ABSTRACT}

Aim/Purpose

We explore impressions and experiences of Information Systems graduates during their first years of employment in the IT field. The results help to understand work satisfaction, career ambition, and motivation of junior employees. This way, the attractiveness of working in the field of IS can be increased and the shortage of junior employees reduced.

Background

Currently IT professions are characterized by terms such as "shortage of professionals" and "shortage of junior employees". To attract more people to work in IT detailed knowledge about experiences of junior employees is necessary.

Methodology

Data from a large survey of 193 graduates of the degree program "Information Systems" at University od Applied Sciences and Arts Hannover (Germany) show characteristics of their professional life like work satisfaction, motivation, career ambition, satisfaction with opportunities, development and career advancement, satisfaction with work-life balance. It is also asked whether men and women gain the same experiences when entering the job market and have the same perceptions.

Findings

The participants were highly satisfied with their work, but limitations or restrictions due to gender are noteworthy.

Recommendations for Practitioners

The results provide information on how human resource policies can make IT professions more attractive and thus convince graduates to seek jobs in the field. For instance, improving the balance between work and various areas of private life seems promising. Also, restrictions with respect to the work climate and improving communication along several dimensions need to be considered.

Future Research More detailed research on ambition and achievement is necessary to understand gender differences.

Accepting Editor: Eli Cohen | Received: November 2, 2018 | Revised: December 6, 2019 | Accepted: December 8, 2019.

Cite as: Disterer, D. (2019). Professional life of information system graduates-Impressions and experiences. Proceedings of the Informing Science and Information Technology Education Conference, Jerusalem, Israel, pp. 413-427. Santa Rosa, CA: Informing Science Institute. https://doi.org/10.28945/4325

(CC BY-NC 4.0) This article is licensed to you under a Creative Commons Attribution-NonCommercial 4.0 International License. When you copy and redistribute this paper in full or in part, you need to provide proper attribution to it to ensure that others can later locate this work (and to ensure that others do not accuse you of plagiarism). You may (and we encourage you to) adapt, remix, transform, and build upon the material for any non-commercial purposes. This license does not permit you to use this material for commercial purposes. 
Keywords professional life, working life, work satisfaction, work-life balance, information systems, graduates, survey, gender

\section{BACKGROUND AND AIM OF THE STUDY}

For some time now, the situation in the field of IT professions is characterized by terms such as "shortage of professionals" and "shortage of junior employees" (Capgemini, 2016; Schmid, GärtigDaugs, \& Förtsch, 2015) and, therefore, much is being done to attract more people to train and work in the field of IT. The low percentage of women in IT degree programs, e.g. $16.5 \%$ in Computer Science and $20.1 \%$ in Information Systems compared to $47.8 \%$ in all other degree programs at German universities (Statistisches Bundesamt, 2016), shows a way to address these shortages, namely by attracting more women to train and work in the field of IT (Stifterverband \& McKinsey, 2016). More importantly: the low percentage of women in IT professions carries the risk of not sufficiently exploiting the potential of women in the IT field. And the lack of women in IT professions may reflect the injustice of certain professions not being equally available to all due to social and cultural barriers (Barton, Devilland, \& Hazlewood, 2015; Camp 2012; Cerf \& Johnson, 2016). Additionally, while recruiting for IT professions, attention must be paid that young people's expectations of and demands on a workplace are different today. When choosing an employer, they increasingly consider factors such as work-life balance and reconciliation of job and family (Urbach \& Ahlemann, 2016).

Against this background, the aim of this study is to gather impressions and experiences of graduates of the Information Systems program (B.Sc.) of the University of Applied Sciences and Arts in Hannover (Germany) in their first years of employment in the IT profession. With the data collected in this study, it is hoped that the job satisfaction of graduates in their early years of professional life can be better understood and areas for improvement identified. The aim is to identify attractants (and restrictions) for working in Information Systems and as a result reduce the shortage of junior IS graduates. The study also aims to examine gender differences in overall experiences and perceptions. This should provide information on which positive impressions and experiences could be used to increase interest in training and working in the field of Information Systems.

Past research revealed professional life in the field of IS mainly characterized by some typical aspects of the occupational culture, such as: predominantly project work and therefore increased time and work pressure, working on several projects at the same time, irregular and sometimes extended working hours, high requirement for advanced training as a result of technical change (Armstrong, Riemenschneider, Allen \& Reid, 2007; Goswami, 2014; Guzman, Stam \& Stanton, 2008; LeRouge, Wiley, \& Maertz, 2013). There are also signs that the culture in IT professions is dominated by men, and (therefore) women are not welcomed in the same way (LeRouge et al., 2013; Pluralsight, 2016; Sumner \& Niederman, 2002; Tapia, Kvasny, \& Trauth, 2004). Graduates aims for professional progress and advancement and are confident that they will achieve this (Coffman \& Neuenfeldt, 2014; Dyke, Duxbury, \& Lam, 2007; Hurrelmann, 2016, LeanIn 2015). We use some of these findings to compare and adjust our results.

When entering professional life, Information Systems graduates gain many different experiences and impressions. In particular, most of them, for the first time, are subject to influencing factors such as work climate and corporate culture. In addition, they work in a field that is characterized by the interdisciplinary quality of Information Systems "between" the fields of Computer Science and Business Administration. To contribute to a better understanding of Information Systems graduates in their first years of employment, the following research questions were included in the study:

- Is working in Information Systems perceived as satisfactory?

- Does the career ambition, as well as the confidence to achieve this, remain for Information Systems graduates in their first years of employment?

- Do graduates manage to achieve a sufficient work-life balance? 
- Is the work climate that graduates encounter sufficiently motivating?

- Are limitations with regard to professional advancement or satisfaction noticed? Are disadvantages perceived due to gender or age?

The topics covered by these questions are considered significant in the current discussion in order to capture the attractiveness of professional fields for young people. Other studies with similar questions are used for comparison and discussion. However, there are currently only a few studies that apply specifically to the field of Information Systems (Ahuja, Ogan, Herring, \& Robinson, 2006; Beyer, 2008; Bischoff \& Strölin, 1988). The majority of studies deal with Computer Science subjects or other STEM (Science Technology Engineering Mathematics) subjects, whereas the differentiation to Information Systems often remains open or vague. Due to the interdisciplinarity of Information Systems, which falls somewhere in "between" the fields of Computer Science and Business Administration, and its strong practical relevance, it can be assumed that the impressions and experiences gained in the professional lives of Information Systems graduates should be viewed in a differentiated manner (Bartol \& Aspray 2006; Beyer, 2008; Whitehouse \& Diamond, 2006; Woszczynski, Myers, $\&$ Beise, 2004).

To capture the professional reality, the study is organized in the form of a survey of graduates in their first years of professional life. To ensure sufficient reliability of the results, a large survey was performed. The study was designed to produce more explorative results, as the key questions cover a relatively broad field of subjects. Previous approaches have been heterogeneous and from various disciplines. For example studies on job satisfaction and motivation, job culture, gender issues and value change. Therefore, there is no comprehensive or overarching theoretical approach. Nevertheless, the data were mainly captured to facilitate analyses and to enable comparisons of the results with other studies.

\section{RESEARCH METHOD}

The bachelor program Information Systems (B.Sc.) at the Business Administration and Computer Science faculty of the University of Applied Sciences and Arts in Hannover (Germany) was introduced in the course of the Bologna process in the winter semester 2005, replacing a long-established Information Systems diploma program. From then until 2015-09-30, in total 340 students had completed this bachelor program; these graduates therefore form the basis (population) of the study. Data collection was completed with a written, structured questionnaire; it seemed appropriate for graduates of an Information Systems program to participate electronically. The questionnaire was developed based on past research (see the respective references in the results section) and together with a group of IS students, which pretested initial sets of questions, and 3 graduates already been active in IS professions, who worked as a trial group. The inputs of both groups triggered some iterations to get the final set of questions.

\section{MEASURES}

In accordance with the research questions of the study regarding impressions and experiences gained by graduates and their satisfaction with employment in the IT profession, dimensions of satisfaction were identified and determined through a series of questions:

- satisfaction with professional life (general),

- satisfaction with opportunities for career advancement/progress, promotions, and development,

- satisfaction with work-life balance,

- satisfaction with work climate,

- satisfaction with equal treatment and perception of disadvantages. 
The satisfaction values for these different topics were determined using a 5-point scales; in addition, special categories were offered to describe any limitations or restrictions. These categories were derived from academic literature that comparisons with other studies. A consistency check of the responses in these categories shows that when choosing as answer "very few limitations" the participants additionally selected only one of the offered limitations or restrictions. This shows that the participants understood the complementarity of the response categories offered.

As independent variables, which could explain differences between levels of satisfaction, primarily gender and duration of working in the profession were considered.

\section{DATA COLLECTION}

The graduates were contacted by email. The personal approach was aimed at encouraging them to participate in the survey and allows the option of reminding them to participate at a later stage. The preparation and organization of the survey was dependent on the availability of address data of the graduates and whether this could be used. The data for all graduates, including last name, first name, gender, graduation date and email address (if available) were extracted from the administrative systems. But current email addresses were not available for all graduates. This necessitated comprehensive research to expand the number of valid mail addresses. For instance, the social online platform Xing was searched to find profiles of graduates in order to ask for the current email address in a personal message. This approach was based on the assumption that many Information Systems graduates were sufficiently tech-savvy and career-oriented as to be member of a social network platform for IS professionals. We investigated profiles on Xing, because it is a well-known European careeroriented social networking site for professionals. This method was successful insofar that email addresses for around 80 graduates could be generated via Xing. Overall for 304 (of all 340) graduates current email addresses were then available. The final number of email addresses used for the call for participation in the survey was greater than the number of 304 graduates, because for some graduates several different addresses were found and used.

The survey platform "surveymonkey" (de.surveymoney.com) was used to administer the survey. This platform has been around for many years and is considered to be robust and reliable. The questionnaire was stored on the platform, and the participants were able to access the questionnaire via WWW, enter their responses, and immediately submit them. The platform is configured in such a way that names, addresses or other identifying items of the participants were not stored. At the end of the survey period, the response data were downloaded from the platform and transferred into evaluation tools.

The graduates were invited to participate in the survey on January 10, 2016 and a reminder was sent to them all on January 17, 2016 the same way. As an incentive, the graduates were promised a small compensation for participating in the survey in the form of a shopping voucher in the amount of $€ 5$ for an online shop.

It is suggested, that the relatively high return rate (see the next sub-section) was due to variety of reasons, e.g. (1) assurance of anonymous handling of the responses, (2) participants were offered a small compensation to participate, (3) the author has been active in the Information Systems program for many years and is known to all participants (at least to some extent), (4) by using the survey platform, participation in the survey was relatively easy and convenient, (5) the design of the questionnaire made sure to avoid any obstacles for the participants.

\section{RETURN RATE AND RESULTING SAMPLE}

A total of 193 responses were received by January 22, 2016. Details on the population and return rate of the survey is presented in Table 1 . With regard to gender distribution, the return rate showed only minimal deviations: The population of 340 graduates contained 70 women $(20.6 \%)$, the sample of 
193 participants in the survey contained 37 women (19.2\%). Hence it can be assumed that the sample does not show a relevant bias with regard to gender.

Table 1: Return rate of the survey

\begin{tabular}{|c|c|}
\hline & Number \\
\hline Number of graduates (2009-01-01 to 2015-09-30 (population) & 340 \\
\hline ... of which email address could not be determined & 36 \\
\hline Number of invitations to participate (graduates with addresses) & 304 \\
\hline ... of which not deliverable ("bounced") with single address & 19 \\
\hline Number of invitations to participate delivered & 285 \\
\hline Number of evaluable responses by 2016-01-22 (sample) & 193 \\
\hline Return rate & $68 \%$ \\
\hline
\end{tabular}

A slight bias was shown in the sample: graduates of "earlier" years (up to 2013) were represented slightly more in the sample than in the population. One reason for this could be the fact that some of the students who graduated in 2014 and 2015 were still enrolled in the Masters course at the time of the survey (January 2016). Therefore, due to the lack of traditional professional experience, they were not eligible to participate in the survey. As the purpose of the study is to determine impressions and experiences of the graduates and their satisfaction with their professional lives, a higher representation of participants with longer professional experience is considered acceptable.

\section{RESULTS}

\section{SATISFACTION WITH PROFESSIONAL LIFE}

Satisfaction with professional life was mainly characterized by some typical aspects of the occupational culture. This included predominantly being involved in project work, resulting in increased time and work pressure, working on several projects at the same time, high work intensity, irregular and sometimes extended working hours, high requirement for advanced training as a result of technical change (Armstrong et al., 2007; Goswami, 2014; Guzman et al., 2008; LeRouge et al., 2013). A high proportion $(87 \%)$ of the surveyed graduates were "very satisfied" or "satisfied" with their professional life, only $3.4 \%$ were "dissatisfied" or "very dissatisfied". On average, the satisfaction values were at 4.09, and therefore approximately at the value "satisfied" on a scale of 1 to 5 where (1) is "very dissatisfied" and (5) is "very satisfied". The differences between the average values for men (4.13) and women (3.94) are small and not significant. This contradicts common assumptions, because the culture in IT professions is dominated by men, and (therefore) women are not welcomed in the same way and are less satisfied with their professional lives (LeRouge et al., 2013; Pluralsight, 2016; Sumner \& Niederman, 2002; Tapia et al., 2004). The satisfaction values of graduates suggested that a pattern of employment acclimatization or adjustment to professional employment was required. In the first years of professional life, satisfaction increased from a value of 3.98 to 4.23 and reached a significantly higher level of satisfaction than "satisfied". A large survey of all graduates (bachelor) of 2013 at German universities of applied sciences (Fabian, Hillmann, Trennt, \& Bridies, 2016) was used as a comparative base for this study. The comparison shows very high levels of satisfaction of the surveyed Information Systems graduates (Figure 1). 


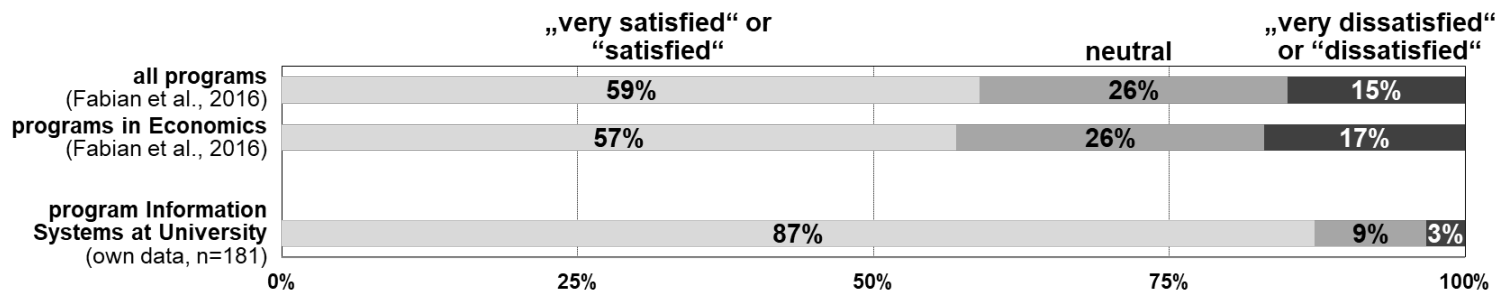

Figure 1 Satisfaction with professional life

The satisfaction of the participants with their professional life was determined through direct questioning, and confirmed with follow-up questions regarding limitations, which may negatively affect the satisfaction with professional life. This showed that that $32 \%$ of the participants experienced "very few limitations" with regard to satisfaction (Figure 2). The most frequently perceived limitations reflect typical characteristics of IT professions, as they relate to conflicts arising from having to work on several projects at the same time, high workload, frequent deadline pressure and fluctuating workload (Armstrong et al., 2007; Goswami, 2014; Guzman et al., 2008; LeRouge et al., 2013). In addition, a lack of promotion and development opportunities was responsible for limitations in work satisfaction for $20 \%$ of the participants.

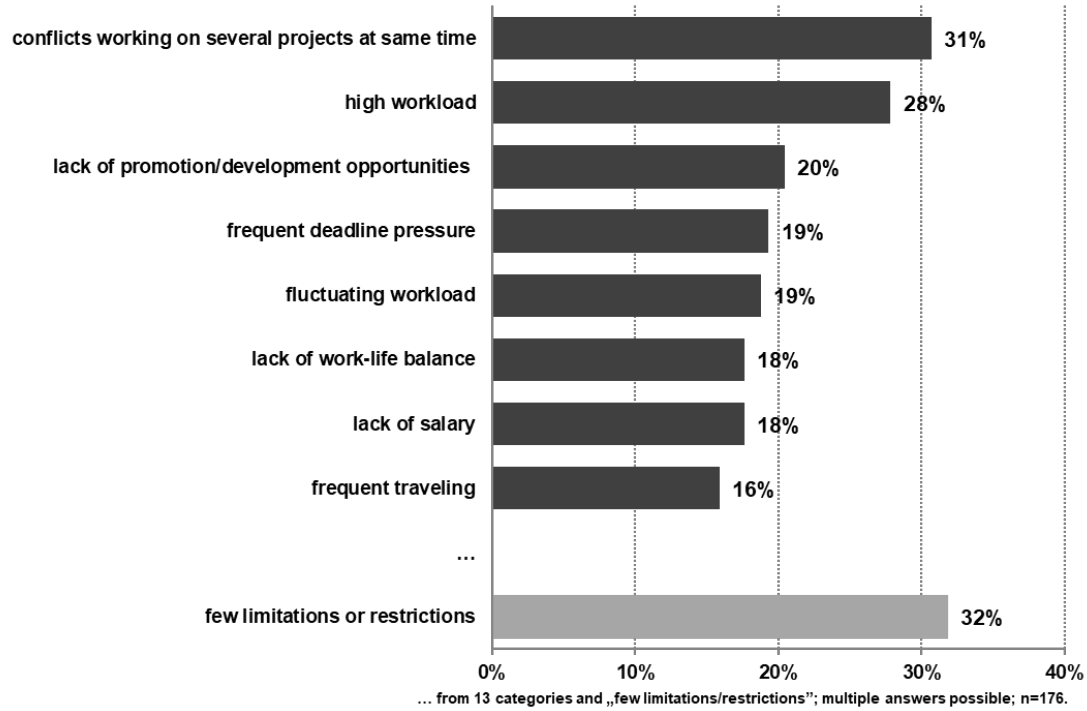

Figure 2 Limitations or restrictions of satisfaction with professional life

Significant differences are shown between men and women in limitations which affect job satisfaction (Figure 3). Whereas men perceive the characteristics, which are considered typical for working in IT professions, as the most frequent limitations, women identified the lack of work-life balance as having a much greater limiting effect on job satisfaction. This argument was also supported by the frequent mention of deadline pressures and frequent travelling. 


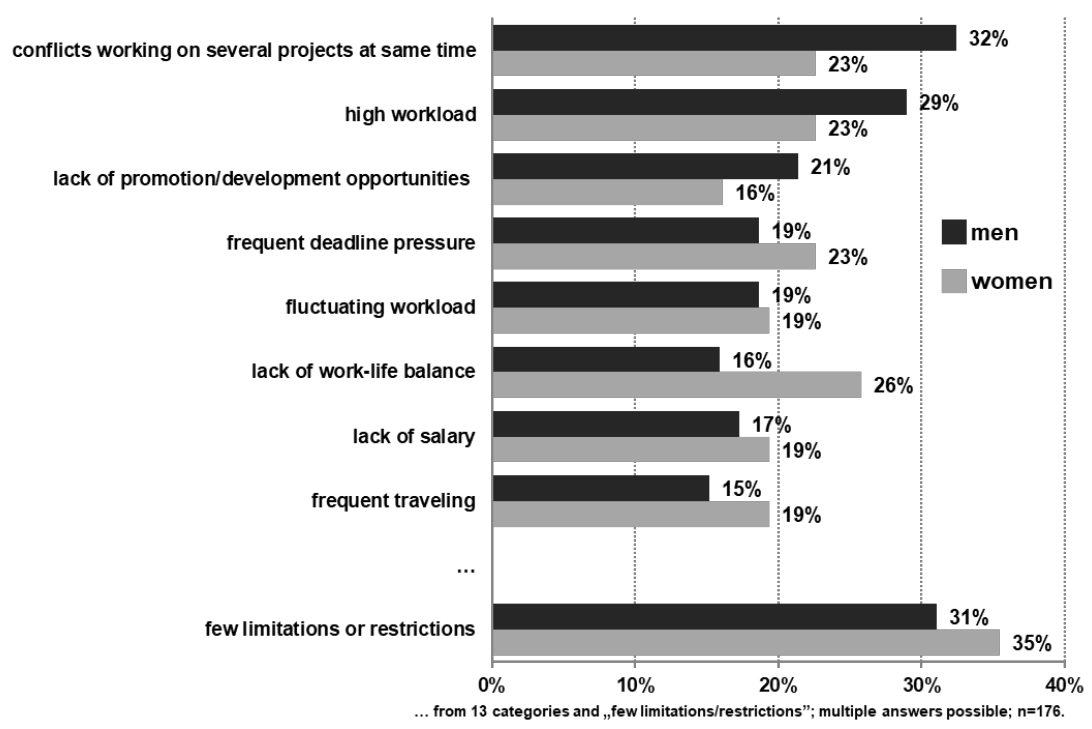

Figure 3 Limitations or restrictions of satisfaction with professional life by gender

\section{CAREER ADVANCEMENT AND PROGRESS}

In the first years of employment in their position graduates aim for career advancement and progress and are confident that they will achieve this. Overall, 95\% agreed that they want to progress and advance in their careers, $89 \%$ believed they will achieve these goals. With a scale of 1 to 5 where (1) is "strongly disagree" and (5) is "strongly agree", the average values for aspirations were at 4.5 and for confidence at 4.3. Fluctuations of the two values during the first years of working were negligible.

However, the differentiation by gender reveals striking differences (Fig 4). Men and women show similar aspirations; average values for striving for progress and advancement in their jobs ("I would like...") were similar, 4.52 for men and 4.48 for women, and therefore confirm the trend that women show similar professional aspirations to men (Dyke et al., 2007; Hurrelmann, 2016). However, the level of confidence of actually achieving this ("I will ...") was significantly lower in women (4.06) $(\mathrm{p}=0.01)$ than in men (4.36).

A differentiation by duration of working shows that women show lower values for both aspiration and achievement after two years. However, these values increase again following longer professional activity (Figure 4). This shows similarities with other studies, in which not only IT professions were surveyed. In one study, which investigated the aspirations for achieving executive and top management positions across all professions, the duration of professional activity was not directly surveyed. Instead, it was differentiated by three different career levels (LeanIn, 2015); the results indicated that on all levels, less women than men have the desire to achieve a "top job". The main cause for this is considered to be the fact that more women want to avoid the pressure and stress caused by these positions, and that they (therefore) have less interest in the respective activities (LeanIn, 2015). A different study showed that more women than men had aspirations at the lower career levels, whilst at the medium and higher levels (significantly) more men had aspirations (Coffman \& Neuenfeldt, 2014). The level of confidence to actually achieve career goals was similar in both women and men. In women, confidence dropped significantly at the medium levels, whereas for men, confidence increased significantly (LeanIn, 2015).

The study presented here shows similar results (Figure 4). The decline of the values of aspiration and achievement in women after working in the profession for around 2 years indicated a certain disillusionment and disappointment. After starting out with similar aspirations and achievement than men, women lost the will to advance and progress in their jobs and the belief that this was possible. This 
could also be interpreted as an indication that the traditionally male dominated IT professions and the work climate and culture in these jobs do not offer sufficient space, recognition and motivation to equally address the aspirations of women and men.
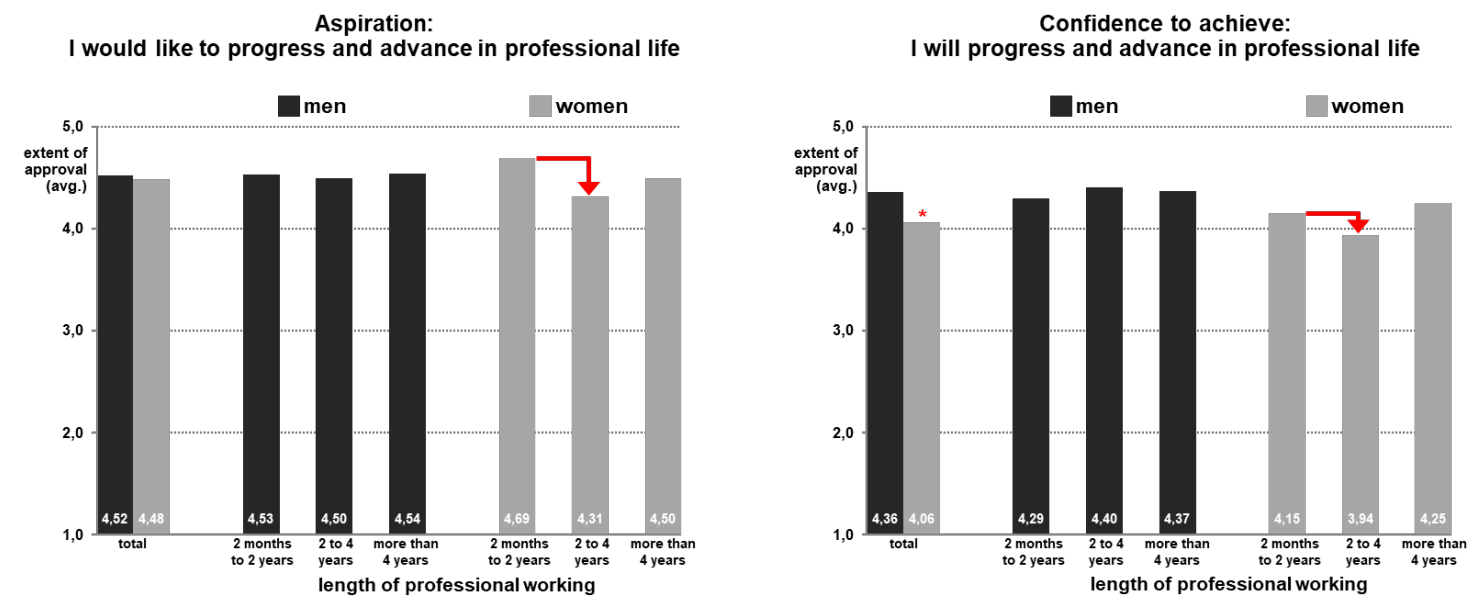

Figure 4 Ambition/Achievement in professional life—by gender

\section{WORK-LIFE BALANCE}

The employment environment for IT professionals has not only been described in terms such as 'shortage of professionals' and 'shortage of junior employees' but the emerging generations are placing more emphasis on appropriate work-life balance (Urbach \& Ahlemann, 2016). In this study, participants average level of their actual work-life balance was found to be 3.6. This is between the options of 'satisfied and 'neutral' on a scale of 1 to 5 where 1 is 'very dissatisfied ' and 5 is 'very satisfied'.

There was little difference between the scores of men (3.63) and women (3.48) in their experience of work-life balance. This accords with the work of Goswami (2014). However, this study also found that the participants perceived that there would be a significant difference in work-life balance for women $(26 \%)$ and men $(16 \%)$.

In examining this topic further, the study found gender differences in several attributes that underpin a construct of 'work-life balance'. These are depicted in Figure 5.

For example, whilst $32 \%$ of men indicated that there were few limitations to attain a desired worklife balance, whereas only 13\% of women indicated there were few limitations for them. Men cited 'sports/hobby', 'social contacts', and 'partnerships/relationships' as issues for them in attaining a desired level of work-life balance. However, the study has not related these findings to experiences in other professions for similar age cohorts. As expected, women cite family related issues as affecting their search for attaining a desired level of work-life balance. This accords with numerous other studies (Ernst \& Young, 2016: Goswami, (2014); Netemeyer, Boles, \& McMurrian, 1996; Riemenschneider, Armstrong, Allen, \& Reid, 2006). 


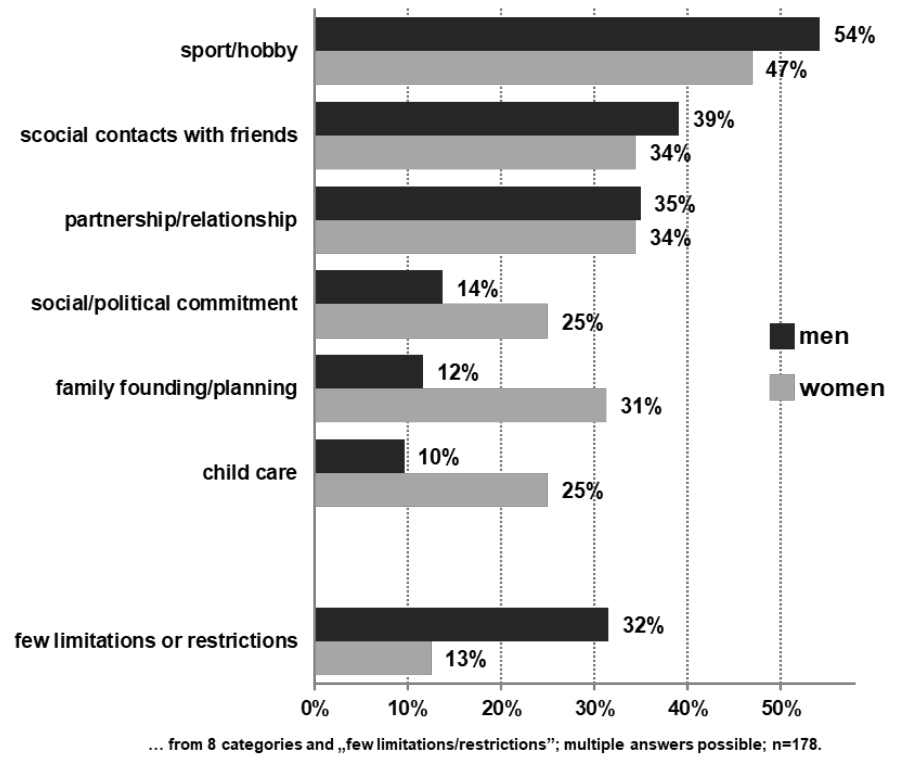

Figure 5 Limitations or restrictions in work-life balance-by gender

\section{SATISFACTION WITH THE WORK CLIMATE}

The value change in upcoming generations has caused expectations for a work climate offering more recognition and appreciation, more respect and more communication at eye level. In this study, participants average level of overall satisfaction with the work climate was 4.08. This is near to the option of "satisfied" on a scale of 1 to 5 where (1) is "very dissatisfied" and (5) is "very satisfied". There was a significant difference $(\mathrm{p}=0.05)$ between scores of men (4.13) and women (3.85). This can be partially explained by different limitations affecting work climate indicated by men and women. Detailed results are given in Figure 6, sorted by differences in proportions by men and women.

A large proportion of the participants $(40 \%)$ perceives very few limitations regrading work climate. The one limitation most frequently indicated (37\%) was the lack of transparency of decisions and management plans. It appears that decisions and plans are not sufficiently communicated and explained, participants felt not well informed, "not included" or "left behind". For almost all offered categories limitations or restrictions, the proportion of women who perceived these limitations was (in part significantly) higher. However, number of cases for more rarely specified categories were very low, i.e. only cautious interpretations are appropriate.

The results accord with other studies, according to which women experience greater dissatisfaction than men with the type and extent of appreciation and recognition prevalent in IT professions (Dyke et al., 2007). Different explanations have been discussed, without having more detailed findings available yet. Women could (simply) require more appreciation and recognition than men in order to perceive a work climate as adequate (Dyke et al., 2007). Or, the male-dominated culture of IT professions is sufficient providing appreciation and recognition for men, however, does not translate well for women. Hence, women perceive a lack of appreciation and recognition. Or, in the maledominated culture, female demeanor and behavior is not as familiar and therefore noticeable; this causes suppression of appreciation and recognition and leads to alienation of female workers (Hurrelman, 2016). Or, the dominance of males in IT professions (LeRouge et al., 2013; Pluralsight, 2016; Sumner \& Niederman, 2002; Tapia et al., 2004) leads to women being appreciated and recognized less, as their work is perceived as less valuable (Dyke et al., 2007). 


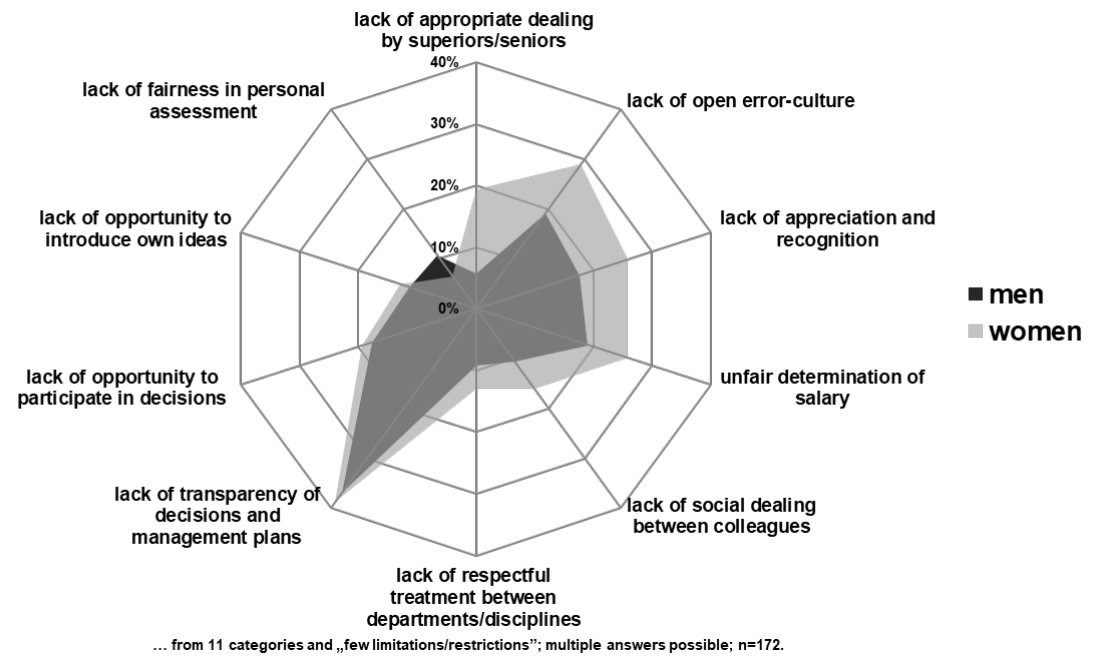

Figure 6 Limitations or restrictions of satisfaction with work climate

\section{EQUAL TREATMENT}

A lack of equal treatment or discrimination is considered as one of the main reasons why less women strive to work in IT professions. In this study, participants' level of satisfaction with equal treatment was at 4.08, which is around the value of "satisfied" on a scale of 1 to 5 where (1) is "very dissatisfied" and (5) is "very satisfied". There was a significant difference $(\mathrm{p}=0.01)$ between scores of men (4.16) and women (3.70) (Figure 7). This accords with the work of other studies that show that women perceive more unequal treatment (Funk \& Parker, 2018; LeanIn, 2015). Differentiated by duration of professional activity (Figure 7) shows higher satisfaction for men and women after a longer period of activity.

A high proportion $(80 \%)$ of all participants perceived "very few limitations" satisfaction with equal treatment. The proportion of men (83\%) was higher than that of women $(67 \%)$. The main reason named by all participants for lack of equal treatment was "age". Taking into account that recent graduates with an average age of 29.7 was asked, this is to be read as "youth discrimination" or a lack of equal treatment of employees with less years of experience. A total of $9 \%$ named this limitation.

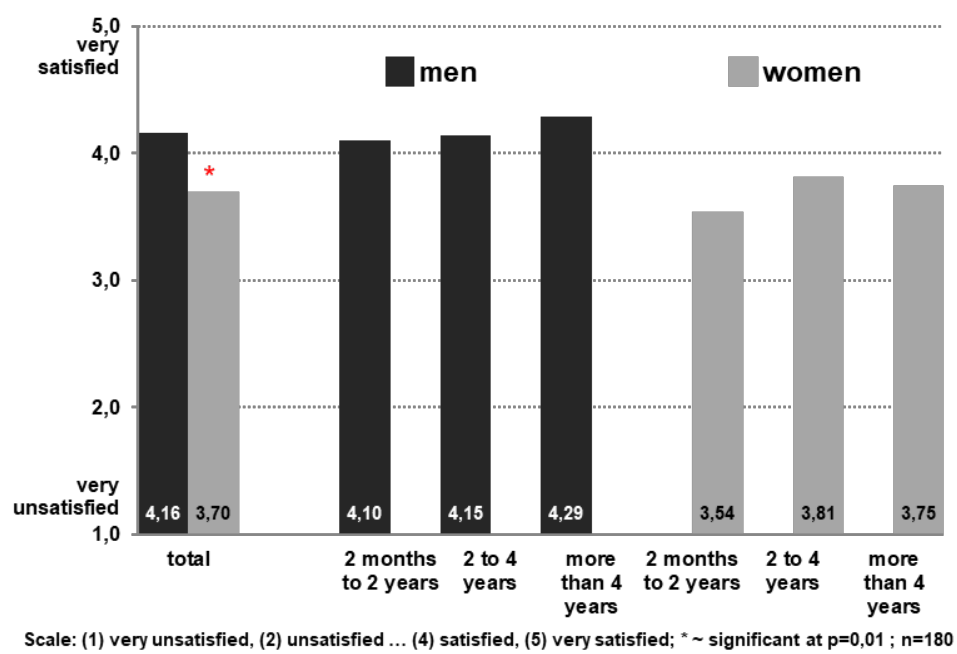

Figure 7 Satisfaction with equal treatment by gender 
The proportion of participants perceiving very few limitations was high (80\%). However, it is conspicuous that $83.5 \%$ of male participants and $66.7 \%$ of female participants chose the option "very few limitations".

\section{IMPLICATIONS AND SUMMARY}

The aim of this study was to gather impressions and experiences of graduates of the Information Systems course (B.Sc.) of the University of Applied Sciences and Arts in Hannover (Germany) in their first years of employment in the IT profession. The return rate of the survey of all graduates from 2009 to 2015 was good, so that the results of the 193 participants (of 340 in total) can read as a portrait of all graduates.

The primary research question to be answered was whether graduates find a satisfactory professional activity in Information Systems. Based on the responses by the graduates the answer to this question was clear: $87.3 \%$ were "very satisfied" or "satisfied" with their professional lives, only $3.4 \%$ were "dissatisfied" or "very dissatisfied" (Figure. 1). In comparison to other comparable studies, these are very good values for satisfaction with professional life (Fabian et al. 2016).

In accordance with this relatively high level of satisfaction, about one third of graduates perceives very few limitations in satisfaction. If limitations were perceived, most often named were conflicts arising from having to work on several projects at the same time and heavy workloads. Men do perceive these two limitations significantly more than women. The mentioned limitations also include phenomena which, in relevant literature, are referred to as occupational culture of the IT profession, such as: deadline pressure, fluctuating working hours and workload. In addition, opportunities for promotion and development are not always sufficiently apparent to the graduates.

Men and women show similarly high aspirations: The average values for men and women for striving for progress and career advancement ("I would like...") were similar and therefore confirm that women show similar professional aspirations to men (Dyke et al., 2007; Hurrelmann, 2016). However, the level of confidence of actually achieving this ("I will ...") was significantly lower in women.

Participants assigns high importance to an appropriate work-life balance. The values differ between men and women, however not significantly. The most frequently named limitations of the work-life balance include areas such as sports/hobby, social contacts/friends and partnership/relationship. This can also be seen as an indication of a normal transition, as work life is generally (even) more demanding than university studies (in terms of time and content). Additionally, for women, the limitations also include the areas of family founding/planning, child care and social/political commitment, which are mentioned much more frequently by women than by men.

This different perception by men and women on the balance between professional and private life such as family founding/planning and childcare is a reflection of two independent phenomena: Firstly, women assign themselves a greater role in family founding/planning and secondly they are subjected to a socially traditional role in child care (Hurrelmann, 2016), which ascribes more responsibility to them for the areas of family founding/planning and childcare (Barton et al., 2015; Fels, 2004; Goswami, 2014; Lojewski, 2011; Riemenschneider et al., 2006); household and family work is traditionally seen as primarily women's work, if it is considered work at all.

In IT professions this should be considered when developing measures to counteract the "shortage of professionals" and "shortage of junior employees", as especially in IT day-to-day work life tends to be less predictable and structured, following the motto "anytime, anywhere" (Barton et al., 2015; Lojewski, 2011). Therefore, measures designed to strengthen the balance between professional work and private life, for example flexible part-time employment, home office, childcare support as well as support for employees returning from parental leave or family leave, are particularly important.

The value change in younger generations might cause the increased expectation of a work climate that offers more recognition and appreciation, more respect and more participation. The limitation 
most frequently named by graduates was the lack of transparency of decisions and management plans. It appears that decisions and plans were not sufficiently communicated and explained, with the result that participants feel "not sufficiently included". Women were more dissatisfied with the work climate; it can be assumed that there is a correlation between this and the less equal treatment perceived by women.

Further insights into the limitations are difficult to interpret, as $80 \%$ of the participants found the category "very few limitations" as appropriate- $83 \%$ of men and $67 \%$ of women. Nevertheless, it is noticeable that the percentage of women who experienced unequal treatment was greater in all offered response categories than that of men.

When trying to reduce the shortage of professionals and junior employees in IT professions by increasing the currently low proportion of women the results of the survey of Information Systems graduates show:

(1) Women show similarly high aspirations as men. The average values for women and men for striving for progress and career advancement in their jobs ("I would like...") were similar; this confirms the trend that women show similar professional aspirations to men (Dyke et al., 2007; Hurrelmann, 2016). However, the level of confidence of actually achieving these goals ("I will ...") was significantly lower in women. It must also be noted that after the first years of professional activity, to a certain extent, women lose the will to advance and progress in their jobs and the belief that this is possible.

(2) Women perceive more limitations in the work-life balance than men: 13\% of women perceive "very few limitations" compared to $32 \%$ of men.

(3) In addition to the limitations in the work-life balance frequently named by all graduates, e.g. the areas of sports/hobby, social contacts/friends and partnership/relationship, the areas of family founding/planning, childcare and social/political commitment were mentioned significantly more frequently by women than by men.

On average, women were less satisfied with the prevailing work climate than men. For almost all categories concerning limitations in work climate offered in the survey, the percentage of women who perceived these limitations was (in part significantly) higher (Figure 6). However, the case numbers for more rarely mentioned categories are low, which means that only cautious interpretations seem appropriate. Nevertheless, the results of other studies are confirmed, according to which women experience greater dissatisfaction than men with the type and extent of the expression of appreciation and recognition prevalent in IT professions (Dyke et al., 2007). Several explanatory approaches are being discussed for this, without more detailed findings being available at present. Women could (simply) require more appreciation and recognition than men in order to perceive a work climate as adequate (Dyke et al., 2007). Or, the male-dominated culture in work life is sufficient as an expression of appreciation and recognition for men, however, does not translate for women to the same extent, with the result that they perceive this as a limitation. Or, in the male-dominated occupational culture, female demeanor and behavior is not as familiar and therefore noticeable; this causes alienation and possibly suppresses appreciation and recognition (Hurrelmann, 2016). Or, the dominance of males in IT professions (LeRouge et al., 2013; Pluralsight, 2016; Sumner \& Niederman, 2002; Tapia et al., 2004) leads to women being appreciated and recognized less, as their work is perceived as less valuable (Dyke et al., 2007).

(5) A part of the dissatisfaction of women could be attributed to the less equal treatment perceived. The survey shows that women were less satisfied with respect to equal treatment than men; $23 \%$ of women directly attribute this unequal treatment to their gender. 
Based on these findings, several measures emerge which have the aim of reducing the "shortage of professionals" and "shortage of junior employees" by attracting more women to IT professions. Human resource policies should improve the balance between work and various areas of private life such as family founding/planning and childcare include, for example, flexible employment, part-time employment, home office work, childcare support as well as support for employees returning from parental leave or family leave. Improving these conditions for Information Systems professionals seems promising.

Also, limitations named by the graduates with respect to the work climate need to be considered; changing or improving communication along several dimensions appears meaningful here. Creating more transparency with regard to decisions and plans by management and a more open approach to errors and problems are needed. A corresponding change of the work and corporate culture-there has been a push for this to happen for quite some time now-seems promising.

The study results also provide information on how human resource policies in corporate practice can make IT professions more attractive and thus convince graduates to seek jobs in the field of Information Systems.

In addition, important insights and follow-up questions can be derived for further research. The job entry phase is formative for the professional life of graduates, which means that aspiration and desire for achievement can be stimulated or curtailed significantly in this phase. More studies are worthwhile. These studies should provide details on how appreciation and recognition can be signaled clearly and appropriately and how-in male-dominated occupational cultures as well-women and men can benefit equally from this.

\section{REFERENCES}

Ahuja, M., Ogan, C., Herring, S., \& Robinson, J. (2006). Gender and career choice determinants in information systems professionals. In N. Niederman \& T. Farrat (Eds.). IT workers: Human capital issues in a knowledgebased environment (pp. 279-304). Greenwich, CT.

Armstrong, D. J., Riemenschneider, C. K., Allen, M. W., \& Reid, M. F. (2007). Advancement, voluntary turnover and women in IT: A cognitive study of work-family conflict. Information \& Management, 44, 142-153. https://doi.org/10.1016/i.im.2006.11.005

Bartol, K., \& Aspray, W. (2006). The transition of women from the academic world to the IT workplace. In J. McGrath-Cohoon \& W. Aspray (Eds.), Women and information technology: Research on underrepresentation (pp. 377-419). Cambridge: MIT Press. https://doi.org/10.7551/mitpress/9780262033459.003.0013

Barton, D., Devillard, S., \& Hazlewood, J. (2015). Gender equality: Taking stock of where we are. McKinsey Quarterly, 4, 86-89.

Beyer, S. (2008). Gender differences and intra-gender differences amongst management information systems students. Journal of Information Systems Education, 19, 301-310.

Bischoff, R., \& Strölin, A. (1988). Erfahrungen von Absolventen des Studiengangs Wirtschaftsinformatik an der Fachhochschule Furtwangen. Angewandte Informatik, 30, 395-404.

Camp, T. (2012). Computing, we have a problem. ACM Inroads, 3, 34-40.

Capgemini (Eds.) (2016). Studie IT-Trends 2016. Retrieved from https://www.capgemini.com/dede/resources/it-trends-studie-2016/

Cerf, V., \& Johnson, M. (2016). Enrollments explode! But diversity students are leaving. Communications of the ACM, 59(4), 7. https://doi.org/10.1145/2898431

Coffman, J., \& Neuenfeldt, B. (2014). Everyday moments of truth - Frontline managers are key to women's career aspirations. Bain \& Company. Retrieved from https://www.bain.com/insights/everyday-moments-of-truth/ 
Dyke, L., Duxbury, L., \& Lam, N. (2007). Do women in high tech create barriers for themselves? In R. Chapman (Ed.), Proceedings of Conference of Australian and New Zealand Academy of Management. Sydney, 1-12.

Ernst \& Young (Eds.) (2016). Studentenstudie 2016 - Studenten in Deutschland: Werte, Ziele, Perspektiven.

Fabian, G., Hillmann, J., Trennt, F., \& Briedis, K. (2016). Hochschulabschlïsse nach Bologna. Hannover.

Fels, A. (2004). Do women lack ambition? Harvard Business Review, 82(4), 50-60.

Funk, C., \& Parker, K. (2018). Women and men in STEM often at odds over workplace equity. Pew Research Center. Washington.

Goswami, S. (2014). Work-life conflict among IT professionals. Journal of Organizational Behavior, 13(4), 38-59.

Guzman, I. R. M, Stam, K., \& Stanton, J. M. (2008). The occupational culture of IS/IT personnel within organizations. Database for Advances in Information Systems, 39(1), 33-50.

Hurrelmann, K. (2016). Sie sind zu langsam! Zeit, 25.5.2016, 65.

LeanIn. (2015). Women in the Workplace. McKinsey \& Co. Retrieved from https://www.mckinsey.com/businessfunctions/organization/our-insights/women-in-the-workplace

LeRouge, C. M., Wiley, J. W., \& Maertz, C. P. (2013). A comparison of job satisfaction between IT and non-IT women incumbents in clerical positions. Database for Advances in Information Systems, 44(2), 39-54. https://doi.org/10.1145/2488968.2488972

Lojewski, J. (2011). Geschlecht und Studienfachwahl - fachspezifischer Habitus oder geschlechtsspezifische Fachkulturen? In P. Bornkessel \& J. Asdonk (Eds.), Der Übergang Schule - Hochschule (pp. 279-348). Wiesbaden: Verlag für Sozialwissenschaften. https://doi.org/10.1007/978-3-531-94016-8 8

Netemeyer, R. G., Boles, J. S., \& McMurrian, R. (1996). Development and validation of work-family conflict and family-work conflict scales. Journal of Applied Psychology, 81, 400-410. https://doi.org/10.1037//0021$\underline{9010.81 .4 .400}$

Pluralsight. (2016). Women in tech careers yearn for female role models and flexibility in the workplace. Retrieved from https://www.pluralsight.com/content/dam/pluralsight/pdfs/landing-pages/b2c/Women In Tech.pdf

Riemenschneider, C. K., Armstrong, D. J., Allen, M. W., \& Reid, M. F. (2006). Barriers facing women in the IT work force. Database for Advances in Information Systems, 37(4), 58-78. https://doi.org/10.1145/1185335.1185345

Schmid, U., Gärtig-Daugs, A., \& Förtsch, S. (2015): Introvertierte Studenten, fleißige Studentinnen?. InformatikSpektrum, 38, 379-395. https://doi.org/10.1007/s00287-014-0784-6

Statistisches Bundesamt (Ed.) (2016). Studierende: Deutschland, Semester, Nationalität, Geschlecht, Studienfach. Retrieved from https://wwwgenesis.destatis.de/genesis/online/logon? sequenz=tabelleErgebnis\&selectionname $=21311-0003$

Stifterverband \& McKinsey (Eds.) (2016). Hochschulbildung für die Arbeitswelt 4.0. Essen.

Sumner, M., \& Niederman, F. (2002). The impact of gender differences on job satisfaction, job turnover, and career experiences of information systems professionals. Proceedings. of SIGCPR 2002, ACM, 154-162. https://doi.org/10.1145/512360.512395

Tapia, A. H., Kvasny, L. \& Trauth, E. M. (2004). Is there a retention gap for women and minorities? In C. Shayo. \& M. Igbaria (Eds.), Strategies for managing IS / IT personnel (pp. 143-164) Idea Group.

Urbach, N., \& Ahlemann, F. (2016). Der Wissensarbeitsplatz der Zukunft. Praxis der Wirtschaftsinformatik HMD, 53(1), 16-28. https://doi.org/10.1365/s40702-015-0192-7

Whitehouse, G., \& Diamond, C. (2006). Gendered dichotomies and segregation patterns in computing jobs in Australia. Labour \& Industry, 16(3), 73-90. https://doi.org/10.1080/10301763.2006.10669331

Woszczynski, A., Myers, M., \& Beise, C. (2004). Women in information technology. In M. Igbaria \& C. Shayo (Edd.), Strategies for managing IS/IT personnel (pp. 165-193). Idea. 


\section{BIOGRAPHY}

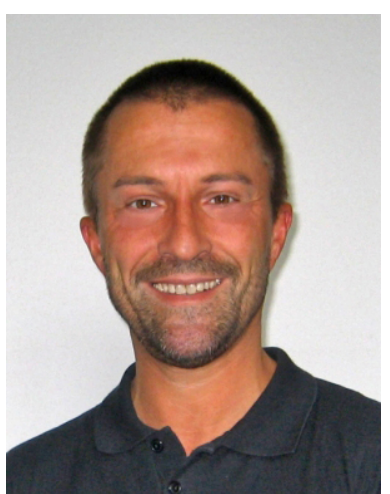

Georg Disterer is professor of Information Management at undergraduate and graduate level at the University of Applied Sciences and Arts Hannover (Germany). He holds degrees in mathematics and business administration and is certified public expert for information systems. Before joining the university he worked as a consultant with international consulting firms and as an administrative director for a professional service firm. 